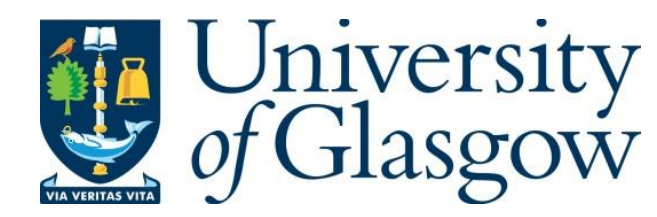

Tuhkanen, H., Piirsalu, E., Nõmmann, T., Karlõševa, A., Nõmmann, S., Czajkowski, M. and Hanley, N. (2016) Valuing the benefits of improved marine environmental quality under multiple stressors. Science of the Total Environment, 551-552, pp. 367-375.

There may be differences between this version and the published version. You are advised to consult the publisher's version if you wish to cite from it.

http://eprints.gla.ac.uk/154105/

Deposited on: 20 December 2017

Enlighten - Research publications by members of the University of Glasgow http://eprints.gla.ac.uk 


\title{
Valuing the benefits of improved marine environmental quality under multiple stressors
}

\author{
Heidi Tuhkanen ${ }^{1}$, Evelin Piirsalư ${ }^{1}$, Tea Nõmmann ${ }^{1}$, Aljona Karlõševa ${ }^{1}$, Sulev Nõmmann ${ }^{1}$, \\ Mikołaj Czajkowski and Nick Hanley ${ }^{3 *}$
}

\begin{abstract}
Many marine ecosystems are under increasing pressure from multiple stressors. In the Baltic Sea, these stressors include oil and chemical spills from shipping, nutrient run-off from land and the introduction of non-indigenous species. All of these pressures have been growing over recent years. Increasing pressures lead to reductions in environmental quality, which produce negative effects on human well-being. In this paper, the choice experiment method is used to estimate the benefits to people in Estonia resulting from reductions in pressure from multiple stressors in the Baltic Sea. The main results show that, firstly, respondents have a positive, statistically-significant willingness to pay to reduce each of the three stressors analysed. Secondly, the average willingness to pay for the improvement in the quality of all Estonian marine waters to achieve Good Environmental Status is around 65 euro per household per year, with a 95\% confidence interval of 48-77 euro. Thirdly, the greatest share of value of this total economic benefit is derived from the willingness to pay for reductions in the risk of large scale oil and chemical spills.
\end{abstract}

\footnotetext{
${ }^{1}$ Stockholm Environment Institute Tallinn Centre, Estonia

* Corresponding author, Department of Geography and Sustainable Development, University of St Andrews, St Andrews KY16 9AJ, Fife, Scotland, UK, ndh3@st-andrews.ac.ukmailto:ndh3@standrews.ac.uk

2 University of Warsaw, Department of Economics, Poland

${ }^{3}$ University of St Andrews, Department of Geography and Sustainable Development, UK
} 
Keywords: multiple stressors; Good Environmental Status; Marine Strategy Framework Directive; marine water quality; choice experiments; oil and chemical spills; eutrophication; non-indigenous species.

Highlights:

- Economic benefits of water quality improvements are estimated

- The case study used is the Baltic Sea; benefits are estimated for Estonia

- Multiple stressors approach is used in a discrete choice experiment framework

- A new approach allowing for non-linear utility function is devised and implemented

Acknowledgements: This study was carried out as a part of the GES-REG project (Good Environmental Status through REGional coordination and capacity building), funded by Central Baltic INTERREG IV A Programme 2007-2013, co-funded by the Environmental Investment Centre of Estonia. MC gratefully acknowledges the support of the Polish Ministry of Science and Higher Education and the Foundation for Polish Science. NH thanks MASTS (www.masts.ac.uk) for funding part of his work. 


\section{Introduction}

The Baltic Sea is often considered to be one of the most polluted seas in the world (WWF, 2011). Baltic Sea ecosystems are impacted by multiple human-derived pressures, such as eutrophication, pollution by hazardous substances, marine transportation, diminishing biodiversity, overfishing, climate change, invasive species, and marine litter (Huhtala et al., 2009; HVM, 2013). Furthermore research has shown that, on average, these pressures act in a synergistic manner, increasing negative impacts beyond what would be anticipated from the addition of independent pressures (Crain et al., 2008; Solan and Whiteley, forthcoming). Thus the combined impact of individual pressures has been a reduction in the environmental quality of many parts of the Baltic Sea ( $\underline{H V M}$, 2013).

The Marine Strategy Framework Directive (MSFD) was adopted by European Union (EU) in 2008 to improve the protection of European marine areas, which form a foundation for marine-related economic and social activities. The MSFD specifically aims to achieve Good Environmental Status (GES) of the EU Marine waters by 2020 (European Commission, 2012a). The Directive requires each EU country, within the framework of their national marine strategy, to provide an assessment of the state of the environment by 2012 and a Programme of Measures (POM) by 2015 through which they plan to reach the GES target by 2020 (European Commission, 2012b). Such measures are best undertaken when the benefits outweigh the costs of implementing these measures. The MSFD requires impact assessments, such as cost-benefit analysis, on the planned programme. In this context, estimates of the benefits of POM implementation should be articulated in monetary terms in order to be comparable with implementation costs.

The support and/or new requirements for socio-economic analysis under policies such as the MSFD and the HELCOM Baltic Sea Action Plan (BSAP; COWI, 2007) have instigated Baltic Seafocused environmental economic research on public preferences. These economic valuations of public preferences of various marine related issues have been performed for the purpose of

providing input to national and trans-national marine policies. Helin et al. (2010) propose a framework for accounting for and valuing the total benefits that society derives from the Baltic 
Sea, through its ecosystem services. While they found that no single valuation method could sufficiently account for the range of values, they note that it is possible to combine stated and revealed preference methods to supplement market value estimates. The transnational study of environmental valuation performed by Ahtiainen et al. (2014) assessed stated public preferences using willingness to pay (WTP) for the management of eutrophication and related distributional effects. Another transnational study by Czajkowski et al. (2015) estimated the change in the value of recreational benefits linked to changes in perceived water quality of the Baltic Sea.

To date, no study has assessed the economic value to Estonian society of changes linked to specific stressors in Estonian marine waters in order to achieve Good Environmental Status. Such benefit calculations are called for in the context of MSFD POM. This paper, therefore, examines the monetary benefits to society of improving the environmental quality of the marine environment which is subject to multiple pressures which have been increasing over time. We focus on the economic benefits of achieving the GES levels by 2020 for the specific MSFD descriptors of eutrophication, concentrations of contaminants (in connection with risk of large-scale oil spills), and the introduction of non-indigenous species, all of which are considered to be among the

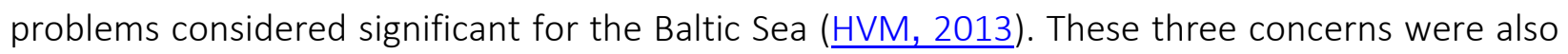
considered relevant for Estonian marine waters according to the expert assessment performed as a part of the process of developing Estonian POM for MSFD (SEI Tallinn et al., 2016). This research estimates the monetary benefits of improvement measures for these three issues through a stated

preferences study applied to the entire Estonian marine area. The analysis assesses people's attitudes towards the environmental quality of the Estonian marine waters, specifically their preferences for alternative policy options for improving the quality to the GES levels specified by the MSFD.

\section{Environmental problems of the Estonian marine area}

The Estonian marine area includes the Gulf of Riga, the Gulf of Finland, the Moonsund Archipelago, as well as Estonian open waters of the Baltic Proper (Figure 1). Despite some differences between 
these basins, they share three main environmental concerns - the risk of large-scale oil and chemical spills and pollution, eutrophication and the introduction of non-indigenous species.

\subsection{Risk of oil and chemical spills and pollution}

The Estonian Initial Assessment for the MSFD concludes that in terms of contamination with hazardous substances, including oil, the state of Estonian waters is "good" in the context of GES, especially compared to other regions of the Baltic Sea (TÜ EMI, 2012). However, the challenging geography of the Baltic Sea (narrow straits, shallow areas, winter ice cover in the Gulf of Finland) combined with heavy and increasing maritime traffic between its busy ports means an increasing risk of major pollution accidents (HELCOM, 2010).

In general, the number and size of ships has increased and is rising. Of the approximately 2,000 ships in the Baltic Sea at any one time, about $20 \%$ are oil tankers which can carry up to 150,000 Mg of oil and are considered high risk. Furthermore, the amount of Russian oil exported through Baltic ports is expected to reach 180 million Mg in 2020 due to improved capacity of Russian oil terminals. Tankers coming from these Russian oil terminals must pass through the Gulf of Finland to get to other oil terminal ports in the Baltic Sea. While no major oil spill has taken place since 2004, 120-140 shipping accidents take place in the Baltic Sea annually (HELCOM, 2009d). These numbers have increased along with traffic. Tankers account for around $10-15 \%$ of the ships involved in accidents. Furthermore, while many tankers are now double hulled, at least two of the 21 tankers involved in accidents in 2012 were single hulled and the hull type for $43 \%$ of the tankers involved in accidents is unknown ( hazardous substances, such as chemicals, also pose a risk (HELCOM, 2010).

There are two aspects of oil and chemical spills which are particularly relevant to this paper. The first is the risk of large-scale oil and chemical spills: the potential frequency or likelihood of a spill which impacts marine waters. Secondly, there is the potential for the oil and chemicals released by such a spill to pollute the coastline. 
Possible measures to reduce the risk of oil and chemical pollution of marine waters include traffic control measures, such as entering into international agreements to improve traffic safety and enhancing traffic control in the Baltic Sea and the Gulf of Finland. Currently, Estonia is a member of the International Maritime Organization as well as the Helsinki Commission, and additionally has a bilateral agreement with Finland on the Cooperation in Combating Pollution in the Marine Environment.

In order to reduce the number of cases of oil and chemical coastal pollution, a number of potential measures can be implemented such as the earlier detection of marine pollution incidents and increased capacity to halt the spread of spills and treat pollutants in the sea once an incident has occurred. This can include measures such as training of all relevant authorities and volunteers, studies on safer operating methods, providing instructions and guidelines on rescue preparedness and rescue operations, and the purchase of new vessels and aircrafts for monitoring (SEI Tallinn et al., 2016). Estonia's capacity for dealing with oil spills is limited to four oil response vessels and equipment, which can be supplemented with smaller oil combating vessels owned by the major ports (Estonian Police and Border Guard Board, 2016). In regards to the "hazardous and noxious substances" type of marine pollution, the current capacity is considered very limited in terms of monitoring capability, response capability, safety equipment, response vessels, and response teams (EMSA, 2013). The current response capability is about half of the recommended HELCOM target response capability (Estonian Police and Border Guard Board, 2016).

\subsection{Eutrophication}

As with oil and chemical spills, the geography of the Baltic Sea is one of the reasons for the sensitivity of the sea to eutrophication. The Baltic is an intensively-used brackish sea with a large catchment area and limited inflows from other water bodies. Eutrophication takes place when excess nutrients, such as nitrogen $(N)$ and phosphorus $(P)$ cause increased growth of algae in water bodies. Inflows of $\mathrm{N}$ and $\mathrm{P}$ originate from atmospheric deposition (significant only for $\mathrm{N}$ ), point 
sources and diffuse sources with links to numerous sectors (agricultural, transportation, and managed forestry and energy sectors ( background sources ( boundaries, nutrients build up over time in the bottom sediments (HELCOM, 2009c).

Due to $\mathrm{P}$ loading from bottom sediments, the Gulf of Finland is the only part of the Baltic Sea where $\mathrm{P}$ concentrations have not fallen over the last 20 years ( $\underline{\text { HELCOM, 2009c) }}$ and it is one of the areas where inorganic nitrogen levels have actually increased (ㅌLCOM, 2014b). Stratification of the water, due to different levels of salinity in the water, limits the oxygenation of bottom layers of water ( $\underline{\mathrm{HELCOM}, 2009 \mathrm{C}})$. The negative impacts of eutrophication include blooms of algae, low underwater light conditions, the emergence of oxygen-depleted zones which cannot support sea life ( $\underline{\text { HELCOM, 2010) }}$ and increased sedimentation of organic matter (Rönnberg and Bonsdorff, 2004). The Estonian Initial Assessment for the MSFD concludes that in terms of eutrophication in Estonian marine waters, the Gulf of Finland is in a "bad" state, the Gulf of Riga is in a "poor" state and the Gulf of Haapsalu, in the Moonsund Archipelago, is in a "very bad" state (TÜ EMI, 2015). The situation with eutrophication has been difficult to improve in the Baltic Sea despite ongoing measures to reduce nutrient inflows ( $\underline{\mathrm{HELCOM}, 2014 \mathrm{~b}})$. Algal blooms can pose threats to human health (Hunter et al., 2012), as well as severely limit recreational and production use of affected waterbodies.

Measures such as the construction of storm-water drainage and treatment systems in harbour cities to improve treatment prior to the release of water to the sea, reduced dumping of untreated wastewater from cruise ships into the sea, and the promotion of environmentally sustainable ship fuels, such as LNG, can be implemented to reduce the inflow of nutrients to the sea. In turn, this can help reduce eutrophication and improve marine water quality with regard to recreation (SEI Tallinn et al., 2016). 


\subsection{Non-indigenous species}

The introduction of non-indigenous species into the Baltic Sea has taken place through shipping, the opening of canals, as well as intentional introduction for aquaculture or fish-stocking purposes. Maritime shipping is a major cause of the introduction of non-indigenous species through the release of ballast waters and hull-fouling. The increase in maritime shipping, along with increases in ship speeds which have improved the survival rates of organisms during voyages, have resulted in an increase in the introduction of non-indigenous species (HELCOM, 2009a). Since the 1960s, Estonian marine waters have become a habitat for 26 non-indigenous species or cryptogenic species (Ojaveer et al., 2011). When non-indigenous species are introduced into suitable environments, they reproduce, spread, become established and can permanently alter that environment ( indigenous species are challenging to assess, but that they can be negative or positive ( 2010). Only a small percentage of the introduced non-indigenous species in the Baltic Sea have had negative impacts determined so far ( potentially cause severe and often irreversible changes ecosystems that might bring economic loss and human health risks (Lovell et al., 2006; Williams and Grosholz, 2008).

The MSFD aims to keep non-indigenous species at a level below which they negatively alter the ecosystem. A reduction in the rate of introduction of non-indigenous species supports this aim. Such a reduction could be achieved by measures such as more stringent requirements for the recovery and treatment of ships' ballast waters in ports, as well as improved monitoring of such actions. This could take place through the ratification and implementation of the International Ballast Water Management Convention. Further potential measures include awareness-raising about non-indigenous species and the risks associated with their introduction into new waters (SEI Tallinn et al., 2016). 


\section{Materials and Methods}

In order to measure the benefits associated with implementing a programme of measures to reduce these pressures to a point where GES could be achieved in Estonian marine waters, and to provide insight into the socially efficient levels of control, we designed and conducted a stated preference valuation study. Stated preference valuation methods allow for the elicitation of economic values for goods that do not have a market price, and enable the calculation of monetary estimates for the peoples' WTP for various improvement scenarios for the selected environmental problems (Hanley and Barbier, 2009; Can and Alp, 2012). We applied the discrete choice experiment (DCE) method to value the improvements in the Estonian waters of the Baltic Sea, including a scenario in which GES is achieved (Justes et al., 2014). In what follows, the design of the choice experiment is first described, followed by the survey procedure.

\subsection{Choice experiment design}

The attributes selected for the discrete choice experiment reflect the issues of Estonian marine waters described above. Table 1 summarizes the attributes used in the experimental design, and the levels these could take.

To determine the levels of the attribute related to the various scenarios, researchers used the data from the Estonian Initial Assessment (TÜ EMI, 2012) which presents the current situation based on data from 2011 for each of these stressors, along with interviews of Estonian experts specialised in water quality issues (Georg Martin, University of Tartu Estonian Marine Institute, personal communication), non-indigenous species (Henn Ojaveer, University of Tartu Estonian Marine Institute, written communication), and oil spills (Sulev Nõmmann, SEI Tallinn, personal communication). With the issues of water quality related to eutrophication and non-indigenous species, the experts involved in the Initial Assessment were asked to provide the forecasts for possible future scenarios as well as the quantitative and qualitative descriptions of the selected levels. In the case of oil spills, SEI Tallinn's internal marine expertise, together with a table on the 
Likelihood of Occurrence of Emergencies risk assessment of the Estonian Ministry of the Interior (2010) were used to produce the forecasts for possible future scenarios and the descriptions of the selected levels. The Estonian Environmental Board further reviewed the forecasts and levels related to the risk of large-scale oil and chemical spills (Teet Koitjärv, Environmental Board, personal communication).

The risk of oil and chemical spills is related to the possibility of accidents involving large-scale oil and chemical pollution (OILECO, 2008). The survey described the current and likely future situation and gave examples of similar events in the past. The situation was described with two separate attributes, which could be targeted separately and which represent different sets of measures: namely, the frequency of large-scale oil and chemical spills ( FLS ) and the probability that oil and chemical pollution reaches the shore (PRS). Actions to reduce oil and chemical pollution are separated into two different attributes because environmental problems increase in significance when pollution reaches the coast. Thus, while it is important to reduce the frequency of accidents, it is also important to prevent coastal pollution. Another reason for distinguishing between these attributes is that different measures are needed to implement reductions in impact. Despite having high risks of a spill due to heavy shipping traffic, current Estonian capacity for prompt clean up and elimination of a spill is lower than in other neighbouring countries (e.g., in Finland). Thus, if such a spill were to occur, the probability of water pollution reaching the coastline would be higher in Estonia than in Finland (OILECO, 2008).

The survey explained to respondents some of the general measures which could be implemented to lower the probability of large-scale oil and chemical pollution of marine waters in the future, and that the current Estonian capacity for discovery of pollution and its prompt elimination was low. The expected frequency of large-scale marine pollution events (FLS) which could be achieved by 2020 was described either as very often (the status quo or baseline level), often, sometimes, or rarely (GES level; see Table 1).

With respect to the probability that pollution can reach coast, the described measures improving both early detection of marine pollution incidents and increased capacity of tackling pollution at 
sea. The probability that (in the event of a large oil of chemical spill) pollution would reach the shore was described either as very high (status quo), high, average, or low (Table 1).

The second water quality problem, eutrophication, was described mainly from the recreational use perspective, using the attribute "water quality" (WQ). The survey explained the sources of nutrient pollution in the Baltic (fertilizer use in agriculture, wastewater) and indicated possible impacts, such as the reduction of water transparency and the amount of algae washed ashore. Respondents were provided with a short list of potential measures which could improve the situation. The descriptions of three possible future levels of eutrophication included a listing of the current and future water transparency levels in different basins and the frequency of large amounts of algae being washed ashore, as well as presenting photo illustrations of the current situation and of GES.

Next, the survey explained what non-indigenous species (NIS) are and discussed how some of these species could become invasive, with the potential to spread and adversely affect biological diversity, ecosystem function, socio-economic values or human health in invaded regions. The text explained how human activity (e.g., shipping) can contribute to spreading non-indigenous species, provided information about the number and dynamics of their changes and included examples and impacts of the most invasive ones currently recorded in Estonian marine waters (e.g., round goby, Harris mud crab and bay barnacle). The text also listed potential measures which could be used to slow down or avert the rate of introduction. It is estimated that the frequency of new nonindigenous species invasions by 2020 could be often (status quo) - 1 new species every 1.5 years on average, rarely - 1 new species every 15-20 years or in exceptional cases (GES) - not more than once every 50 years.

The final attribute represented the cost (cost) associated with each policy alternative. This was the price that respondents would have to pay for the policy to be implemented. The questionnaire explained that additional policy actions required additional spending by Estonian public authorities, and that any action programme would therefore need to be funded by additional annual taxes. Previous studies performed in the Baltic Sea region show that such a tax is an appropriate vehicle for payment for such policy options (Ahtiainen et al., 2013). 


\subsection{Survey implementation}

The survey consisted of four parts and included 47 questions. The first part provided information about the study area and covered questions about the respondent's connections (if any) to Estonian marine waters. The second part contained information and questions related to the multiple stressors within Estonian marine waters. The third part included the choice experiment questions (12 choice tasks) regarding measures for the improvement of the environmental state of Estonian marine waters. The fourth part related to personal information about the respondent, including environmental knowledge and questions concerning demographics.

The survey contained 3 blocks of 12 choice tasks, in which respondents were asked to choose from the status quo policy, representing no additional actions and with no additional tax being levied, and 2 alternative policy options which would lead to some improvement in environmental quality but at a cost to the respondent. The experimental design was prepared using NGENE software. The first of the designs (used for 150 respondents in the pilot study) was D-efficient with fixed 0 priors (Scarpa and Rose, 2008). The updated designs, administered to the subsequent 250 and 300 respondents, used Bayesian, normally distributed priors with means derived from the MNL models estimated based on the samples available at the time and arbitrarily selected standard deviations, usually between $20-50 \%$ of the estimates with some absolute minimum for the priors very close to zero (Bliemer et al., 2008). Respondents were asked to choose the preferred alternative in each of the choice tasks while taking into account the cost incurred with each option. An example choice task is shown in Figure 2.

The paper-based version of the survey was pre-tested in Estonian and Russian languages. After initial modifications, an online pilot survey was conducted with a quota sample of 150 respondents. As no major changes to the survey took place after the pilot, the observations from the pilot were included in the further analysis. The main survey was conducted in December 2013 as an online survey which gathered opinions from 550 Estonian residents. The number of respondents from the pilot and the main survey totalled 700 . 
The online survey was conducted by a professional survey company using the Norstat web-panel of 25,000 people in Estonia. In order for the results of the questionnaire to be extrapolated to the Estonian population, the objective was to have a sample of 700 responses which was proportionally representative of Estonian population by age group, gender, nationality and place of residence. Quotas were used to guarantee representativeness. The survey had a 41,6\% response rate for the 3921 emailed invitations. The difference between the 700 surveys used and the number of responses can be accounted for by over-quota respondents and partially finished responses. The response time was also recorded for each of the survey responses.

\subsection{Statistical modelling approach}

In what follows we infer respondents' preferences and willingness to pay for improvements in the environmental quality of the Baltic Sea from the choices they made in the choice experiment. Theoretical foundations for quantitative modelling of consumers' utility functions are provided by the random utility theory (McFadden, 1974). Standard practice in modelling consumers' preferences using discrete choice data are the multinomial logit (MNL) and the mixed logit (MXL) models (Hess and Daly, 2014; Hensher et al., 2015). In the MNL model all respondents are assumed to have exactly the same preference parameters, while in the MXL model respondents' coefficients can differ and are assumed to follow an a priori specified multivariate parametric

distributions. The data collected from the discrete choice experiment allows for the estimation of the coefficients of respondents' utility functions, i.e. quantitatively model their preferences. Given that we wish to estimate WTP for the non-monetary choice attributes, it is convenient to use a money-metric utility function (estimate preference parameters in WTP space, Train and Weeks, 2005), which makes it possible to interpret the estimated coefficients as respondents' marginal WTP for the associated choice attributes levels. 


\subsection{Accounting for non-linearities in the utility function.}

In the economic model of choice and value, the utility function is the main device used to represent the issues which people care about, and the relative values which they attach to these aspects of well-being. Choice experiment studies typically assume that respondents' utility is a linear function of the choice attributes. This clearly does not need to be the case. There are two possible ways to allow for a non-linear relationship between utility and explanatory variables. The first relies on dummy or effects coding the explanatory variable and having the effects for all but one level enter the utility function, instead of the continuous (linear) variable. This approach can be useful in cases when only a few levels of the explanatory variable are observed - more levels require more model parameters, which can lead to identification or convergence problems, especially in the case when coefficients are random and correlated. In addition, this approach often leads to less robust predictions.

The alternative approach involves introducing a non-linear transformation of the explanatory variable (e.g., using its logarithm). The problem here, however, lies with selecting the appropriate transformation. As there are virtually infinite transformations, trying a few typical cases and checking which fits the data best is a tedious and incomplete task. One way to mitigate this problem is to parametrize the transformation of the explanatory variable and minimize the loglikelihood function including the additional transformation parameter as a variable. A convenient transformation which could be used in this case is the Box-Cox transformation (Spitzer, 1982), defined as:

$$
f(x, \lambda)=\left\{\begin{array}{lll}
\frac{x^{\lambda}-1}{\lambda} & \text { if } & \lambda \neq 0 \\
\log (x) & \text { if } & \lambda=0
\end{array} .\right.
$$

The approach has been used in environmental economics before (Czajkowski and Ščasný, 2010; Barbier et al., forthcoming), but we are aware of only one application of this method to DCE data, to investigate the non-constant marginal utility of respondents' income (i.e. the cost damping effect, Budziński, forthcoming). 
In this paper, we propose an alternative way to find the best fitting transformation - the YeoJohnson transformation (Yeo and Johnson, 2000). It is defined in the following way:

$$
f(x, \lambda)=\left\{\begin{array}{lll}
\frac{(x+1)^{\lambda}+1}{\lambda} & \text { if } & x \geq 0 \wedge \lambda \neq 0 \\
\log (x+1) & \text { if } & x \geq 0 \wedge \lambda=0 \\
\frac{-(-x+1)^{2-\lambda}+1}{2-\lambda} & \text { if } \quad x<0 \wedge \lambda \neq 2 \\
-\log (-x+1) & \text { if } \quad x<0 \wedge \lambda=2
\end{array} .\right.
$$

The Yeo-Johnson transformation has similar properties to the Box-Cox transformation for positive values - it incorporates many typically used transformations and can be used for reducing skewness and to approximate normality. Its main advantage, however, is that it is defined on the whole real line and hence can be used for explanatory variables which are both positively and negatively valued. In what follows we apply this method to find the transformation of explanatory variables which fits our data best.

\section{Results}

Some 150 individuals were identified as "protest zero" respondents and thus were removed from further analysis. These were respondents who stated that they would not be 'willing to pay anything in principle to improve the Estonian marine environment quality concerning the described problems' and, at the same time, claimed that they 'do not believe that the environmental state of Baltic Sea can be improved' or that 'people and enterprises who pollute the sea should pay'. Such individuals are not signalling that they place a zero economic value on the environmental improvements contained within the choice experiment, but are rather questioning the possibility of reaching the improved state or the fairness of the situation in which they would have to pay for that improvement. For the remaining responses, the discrete choice experiment data was used to model their preferences using the approach outlined in Section 3. 
The models were estimated using custom code developed in Matlab which is made available upon request, along with the translation of the original questionnaire and dataset. In the MXL models, all attribute coefficients are random and freely correlated; all coefficients were assumed to be normally distributed, with the exception of the coefficient representing the product of the scale and marginal utility of income $\sigma_{i} a_{i}$, which was assumed to follow lognormal distribution to constrain its sign. For the lognormally distributed coefficient, the estimated mean and standard deviation of the underlying normal distribution is reported. The cost enters the model with a negative sign and was scaled by a factor of 100 to facilitate convergence.

Table 2 presents the results of the MNL and MXL models in two versions - with and without applying the Yeo-Johnson transformation to the two continuous explanatory variables representing the risks associated with large-scale oil and chemical spills and pollution. The models are estimated in Willingness To Pay space and hence the coefficients of the non-monetary attributes can readily be interpreted as marginal WTP (in EUR) for changes in each of the attribute levels.

Overall, the results show that all the choice attributes are significant explanatory variables of respondents' choices and are of the expected sign. As is typically the case, the MXL models which are able to account for unobserved preference heterogeneity provide a considerable improvement to the MNL models, as is indicated by the significant coefficients for the standard deviations of the preference parameters, as well as the better fit and prediction measures. The respondents are WTP to reduce the frequency of large-scale oil spills and the probability that pollution would reach the shore, prefer alternatives with 'moderate' and 'good' water quality (vs. the reference 'poor' quality), and prefer alternatives which incorporate measures leading to less frequent introduction of new non-indigenous species. Interestingly, "major" improvements in the last two attributes were valued only slightly more than "medium" improvements.

Including the non-linear transformation of the FLS and PRS parameters leads to significant improvement in the model fit (as indicated by the LR test results, higher McFadden's pseudo- $R^{2}$ and lower Akaike Information Criterion values) and predictive power (higher values of the panel version of the Ben-Akiva-Lerman's pseudo- $\mathrm{R}^{2}$, representing mean probability of correct choice 
predictions of the model). The non-linear transformation parameters are both significantly different from unity (which would imply a linear relationship) - with the parameter of PRP indicating convex and the parameter of FLS - concave relationship between respondents' WTP and the frequency or probability reduction levels.

To provide an illustration of the impact of introducing the Yeo-Johnson transformation of the explanatory variables, we simulated the implied non-linear relationship between respondents' mean WTP and the expected reduction in the frequency of large-scale oil and chemical spills and the probability that pollution would reach the shore (Figure 3). The relationship between WTP and FLS levels does appear highly non-linear and strictly convex. While there are relatively low gains in decreasing the frequency from the baseline level of 1 event every 2 years on average, the function quickly becomes much steeper and WTP for reductions to 1 event every 300 years on average becomes close to 20 EUR. In the case of PRS, the relationship is concave, similar to the logarithm function. In this case, the differences between the linear and non-linear relationships between WTP and probability reductions are less stark, although still visible.

Overall, introducing the non-linear transformation to the DCE model allows for the identification of nonlinearities and provides a means of describing them using smooth functional forms. This is advantageous as a means of providing predictions of WTP for all levels of the attributes in between the observed levels, as well as beyond them. While the differences between the fitted linear and non-linear functions for the reduction levels close to where most observations were available (FLS $\approx 0.5, \mathrm{PRS} \approx 1$ ) are low, the differences clearly become larger for out-of-sample predictions (Figure 3).

Finally, given our focus on estimating the Estonian population's WTP for the Estonian marine waters to reach the Good Environmental Status, and because the WTP for a scenario is not necessarily equal to the sum of marginal WTP, we used the estimation results in Table 2 to simulate the economic benefits associated with changes in multiple attribute levels. The scenario includes changes in the following attributes: reduction in FLS from $1 / 2$ to $1 / 300$, reduction of PRS from 0.99 to 0.25 , reaching 'good' water quality level for recreation and reducing the risk of introducing new non-indigenous species to 'in exceptional cases'. The results are provided in Table 3. An average 
Estonian household would be WTP close to 65 EUR for reaching GES in the Estonian marine waters. The result is highly significantly different from zero (95\% confidence interval of 48-77 EUR) and can be used for a comparison of the economic benefits of meeting GES with the anticipated per person cost of the actions which are expected to bring these changes about.

In the simulated scenario, the total WTP of 65.73 EUR per household can be broken down to the various attributes of GES. 26\% of the total WTP can be attributed to the reduction in the frequency of large-scale oil spills, 30\% to the reduction in the probability that in the case of a spill, pollution will reach the shore, $27 \%$ to the improvement in water quality and $16 \%$ to the reduction of the risk of introducing the new non-indigenous species. Each of these values can be separately compared with the cost of implementing the relevant actions (per household) to decide if such a policy is economically justified.

\section{Discussion and Conclusions}

The environmental quality of Estonian marine waters is adversely impacted by three principle stressors: nutrient inputs, oil and chemical spills, and the introduction of non-indigenous species. These pressures have been increasing over recent years. Measures which can be taken to reduce these pressures are costly, and within the Marine Strategy Framework Directive there are provisions for national governments to compare the economic benefits and costs of programmes of measures for achieving Good Environmental Status. This study uses the choice experiment method to estimate the relative economic values of changes to each of the three stressors noted above, and then brings together an overall estimate of the value to Estonian society of an improvement of the Estonian marine waters to the Good Environmental Status level.

Choice experiments, as one example of the environmental valuation methods which have been developed by economists over the last 40 years, can provide much useful information in the context of managing resources which are under pressure from multiple stressors. Of particular focus here are the questions of whether the economic benefits of a package of actions to alleviate 
these pressures and reach a particular environmental target outweigh the costs of such a package; and how relative economic values vary across these multiple stressors. This latter is an important consideration, since management actions are typically aimed at individual stressors (for example, oil pollution, in this case). Economic valuation of such problems can also cast light on which sections of society benefit most from improvements in environmental quality. Whilst this kind of information is useful in evaluating the likely social acceptability of actions to reduce multiple stressors and the distribution of gains and losses from such actions, we do not focus on these distributional aspects in the current paper.

The main results which emerge from our choice experiment are that, firstly, respondents have a positive, statistically-significant willingness to pay to reduce each of the three stressors modelled. Secondly, average willingness to pay for an improvement in the quality of all Estonian marine waters to Good Environmental Status is around 65 euro per household per year, with a 95\% confidence interval of 48-77 euro. Thirdly, of this total economic benefit figure, the greatest proportion of value is derived from the willingness to pay for reductions in the risks of large-scale oil and chemical spills. Decreases in the introduction of new non-indigenous species are valued lower than reductions in other stressors in the study. To derive these results, we developed a new statistical approach to investigate and then represent potential non-linearities in respondents' utility functions. However, whilst utilising this approach provided a better-fitting model for this data, it produced very little change in willingness to pay estimates.

It is perhaps somewhat surprising that the choice experiment revealed that respondents were willing to pay a substantial amount for improvements in their marine environment, as only $21 \%$ percent of respondents initially stated that they were, in principle, willing to pay anything to improve the marine water quality in Estonia. Furthermore, only about a quarter of the people felt that the current quality of Estonian marine waters limited their leisure possibilities. However, respondents appear to have correctly differentiated between the current environmental quality in the Baltic Sea as they perceive it, and the status quo (SQ) scenario used in the choice experiment. That SQ scenario was based on a situation where taking no additional actions today will lead to a decline in environmental quality in the future. Respondents might, therefore, not 
have been willing to see a further decline in environmental quality of Estonian marine waters compared to the present situation. Moreover, the reasons for choosing an improvement over the SQ scenario used in the choice experiment will extend beyond wanting improved leisure possibilities, since they will also include benefits from maintaining a healthier ecosystem for future generations.

Finally, it is important to note that changes in the environmental quality of Estonian marine waters depend not only on future actions taken by Estonia, but also on actions taken by its neighbouring countries. Environmental quality of the Baltic Sea depends on pressures which originate in the production and consumption decisions of all nine countries around the Baltic Sea, and on trade patterns across the Baltic Sea (since this effects marine traffic). It is quite possible that willingness to pay for actions which reduce the environmental pressures which any one country has some leverage over will depend partly on the actions its citizens believe that other Baltic Sea countries are undertaking to reduce eutrophication, limit risks from oil and chemical spills, or reduce the introduction of non-indigenous species. This might be both because citizens in each country wish for all other countries around the Baltic Sea to take on a "fair share" of the costs of improvements, and because they recognise the fundamental inter-connectedness of actions in all nine Baltic Sea countries in terms of marine water quality. This dependence on the economic benefits to a given country on the actions of other to improve a shared, common-property environmental resource has also been found in the context of climate change (Lee and Cameron, 2008), so could well also exist for the case of the Baltic Sea. 


\section{References}

Ahtiainen, H., Artell, J., Czajkowski, M., Hasler, B., Hasselström, L., Huhtala, A., Meyerhoff, J., Smart, J. C. R., Söderqvist, T., Alemu, M. H., Angeli, D., Dahlbo, K., Fleming-Lehtinen, V., Hyytiäinen, K., Karlõševa, A., Khaleeva, Y., Maar, M., Martinsen, L., Nõmmann, T., Pakalniete, K., Oskolokaite, I., and Semeniene, D., 2014. Benefits of meeting nutrient reduction targets for the Baltic Sea - a contingent valuation study in the nine coastal states. Journal of Environmental Economics and Policy:1-28.

Ahtiainen, H., Artell, J., Czajkowski, M., Hasler, B., Hasselström, L., Hyytiäinen, K., Meyerhoff, J., Smart, J., Söderqvist, T., Zimmer, K., Khaleeva, J., Rastrigina, O., and Tuhkanen, H., 2013. Public preferences regarding use and condition of the Baltic Sea - an international comparison informing marine policy. Marine Policy, 42:20-30.

Barbier, E. B., Czajkowski, M., and Hanley, N., forthcoming. Is the income elasticity of the willingness to pay for pollution control constant?

Bliemer, M. C. J., Rose, J. M., and Hess, S., 2008. Approximation of Bayesian Efficiency in Experimental Choice Designs. Journal of Choice Modelling, 1(1):98-127.

Budziński, W., forthcoming. The effects of non-constant marginal utility of cost for public goods valuation [Znaczenie zmienności krańcowej użyteczności kosztu ponoszonego przez konsumenta dla wyceny dóbr nierynkowych]. Ekonomia.

Can, Ö., and Alp, E., 2012. Valuation of environmental improvements in a specially protected marine area: A choice experiment approach in Göcek Bay, Turkey. Science of the Total Environment, 439:291-298.

COWI, 2007. Economic analysis of BSAP with focus on eutrophication - Interim Report. Report 2(1) to HELCOM, COWI Group Consulting.

Crain, C. M., Kroeker, K., and Halpern, B. S., 2008. Interactive and cumulative effects of multiple human stressors in marine systems. Ecology letters, 11(12):1304-1315.

Czajkowski, M., Ahtiainen, H., Artell, J., Budziński, W., Hasler, B., Hasselström, L., Meyerhoff, J., Nõmmann, T., Semeniene, D., Söderqvist, T., Tuhkanen, H., Lankia, T., Vanags, A., Zandersen, M., Żylicz, T., and Hanley, N., 2015. Valuing the commons: An international study on the recreational benefits of the Baltic Sea. Journal of Environmental Management, 156:209-217.

Czajkowski, M., and Ščasný, M., 2010. Study on benefit transfer in an international setting. How to improve welfare estimates in the case of the countries' income heterogeneity? Ecological Economics, 69(12):2409-2416.

EMSA, 2013. Inventory of EU Member States' Policies and Operational Response Capacities for Hazardous and Noxious Substances Marine Pollution. European Maritime Safety Agency.

Estonian Ministry of the Interior, 2010. Guidelines for risk assessment of emergencies [Hädaolukorra riskianalüüsi koostamise juhend]. https://www.riigiteataja.ee/aktilisa/0000/1327/9238/13280803.pdf.

Estonian Police and Border Guard Board, 2016. Marine pollution control equipment and techniques [Merereostustõrjevahendid ja -tehnika]. Estonian Police and Boarder Guard Board website: 
https://www.politsei.ee/et/teenused/merereostustorje/merereostustorjevahendid-jatehnika.dot, accessed: 2016-01-26.

European Commission, 2012a. Marine ecosystems under the weather. The European Commission's commitment to cleaner seas and oceans by 2020.

European Commission, 2012b. A Marine Strategy Directive to save Europe's seas and oceans. European Commission Website http://ec.europa.eu/environment/water/marine/directive en.htm.

Hanley, N., and Barbier, E. B., 2009. Pricing Nature. Cost-Benefit Analysis and Environmental Policy. Edward Elgar, Edward Elgar, Cheltenham, UK and Northampton, MA, USA.

HELCOM, 2005. Nutrient pollution to the Baltic Sea 2000. Baltic Sea Environment Proceedings, 100:1-24.

HELCOM, 2009a. Biodiversity in the Baltic Sea - An integrated thematic assessment on biodiversity and nature conservation in the Baltic Sea. Baltic Sea Environment Proceedings, 116B.

HELCOM, 2009b. Eutrophication in the Baltic Sea - An integrated thematic assessment of the effects of nutrient enrichment and eutrophication in the Baltic Sea region. Baltic Sea Environment Proceedings, 115B.

HELCOM, 2009c. Eutrophication in the Baltic Sea - An integrated thematic assessment of the effects of nutrient enrichment and eutrophication in the Baltic Sea region: Executive Summary. Baltic Sea Environent Proceedings, 115A.

HELCOM, 2009d. Report on shipping accidents in the Baltic Sea area for the year 2008.

HELCOM, 2010. Maritime Activities in the Baltic Sea - An integrated thematic assessment on maritime activities and response to pollution at sea in the Baltic Sea Region. Baltic Sea Environment Proceedings, 123.

HELCOM, 2014a. Annual report on shipping accidents in the Baltic Sea area during 2012. http://www.helcom.fi/Lists/Publications/Annual\%20report\%20on\%20shipping\%20accide nts\%20in\%20the\%20Baltic\%20Sea\%20area\%20during\%202012.pdf.

HELCOM, 2014b. Eutrophication status of the Baltic Sea 2007-2011 - A concise thematic assessment. Baltic Sea Environment Proceedings, 143.

Helin, J., Artell, J., and Ahtiainen, H., 2010. From ecosystem services to benefits of the Baltic Sea indicators and threats. Nordic Council of Ministers, Nordic Council of Ministers Secretariat.

Hensher, D. A., Rose, J. M., and Greene, W. H., 2015. Applied Choice Analysis. 2 Ed., Cambridge University Press.

Hess, S., and Daly, A., eds. 2014. Handbook of choice modelling. Edward Elgar, Northampton, MA. Huhtala, A., Ahtiainen, H., Ekholm, P., Fleming-Lehtinen, V., Heikkilä, J., Heiskanen, A.-S., Helin, J., Helle, I., Hyytiäinen, K., Hällfors, H., Iho, A., Koikkalainen, K., Kuikka, S., Lehtiniemi, M., Mannio, J., Mehtonen, J., Miettinen, A., Mäntyniemi, S., Peltonen, H., Pouta, E., Pylkkö, M., Salmiovirta, M., Verta, M., Vesterinen, J., Viitasalo, M., Viitasalo, F. S., and Väisänen, S., 2009. The economics of the state of the Baltic Sea: pre-study assessing the feasibility of a cost-benefit analysis of protecting the Baltic Sea ecosystem. Sektoritutkimuksen neuvottelukunnan julkaisuja, 2:1-170.

Hunter, P. D., Hanley, N., Czajkowski, M., Mearns, K., Tyler, A. N., Carvalho, L., and Codd, G. A., 2012. The effect of risk perception on public preferences and willingness to pay for 
reductions in the health risks posed by toxic cyanobacterial blooms. Science of the Total Environment, 426(1):32-44.

HVM, 2013. State of the Baltic Sea. Background Paper. Havs- och vattenmyndigheten report.

Justes, A., Barberán, R., and Farizo, B. A., 2014. Economic valuation of domestic water uses. Science of the Total Environment, 472:712-718.

Lovell, S. J., Stone, S. F., and Fernandez, L., 2006. The economic impacts of aquatic invasive species: a review of the literature. Agricultural and Resource Economics Review, 35(1):195.

McFadden, D., 1974. Conditional Logit Analysis of Qualititative Choice Behaviour. In: Frontiers in Econometrics, P. Zarembka, ed., Academic Press, New York, NY, 105-142.

OILECO, 2008. Integrating ecological values in the decision making process on oil spill combating in the Gulf of Finland. final report.

Ojaveer, H., Eek, L., and Kotta, J., 2011. Handbook of aquatic alien species of Estonia. Vee võõrliikide käsiraamat (in Estonian). Tallinn.

Rönnberg, C., and Bonsdorff, E., 2004. Baltic Sea eutrophication: area-specific ecological consequences. Hydrobiologia, 514(1-3):227-241.

Scarpa, R., and Rose, J. M., 2008. Design Efficiency for Non-Market Valuation with Choice Modelling: How to Measure it, What to Report and Why. Australian Journal of Agricultural and Resource Economics, 52(3):253-282.

SEI Tallinn, Marine Systems Institute of Tallinn University of Technology, and Estonian Marine Institute of University of Tartu, 2016. Estonian Programme of Measures for Marine Strategy Framework Directive. Technical report.

Solan, M., and Whiteley, N., forthcoming. Stressors in the Marine Environment. Oxford University Press.

Spitzer, J. J., 1982. A Primer on Box-Cox Estimation. The Review of Economics and Statistics, 64(2):307-313.

Train, K. E., and Weeks, M., 2005. Discrete choice models in preference space and williingness-topay space. In: Applications of simulations methods in environmental and resource economics, R. Scarpa and A. Alberini, eds., Springer, Dordrecht.

TÜ EMI, 2012. Initial Assessment of Estonian Marine area [Eesti mereala keskkonnaseisundi esialgne hindamine]. Tartu University Marine Institute, Tallinn.

TÜ EMI, 2015. Monitoring of the Estonian Coastal Waters 2014 [Eesti rannikumere operatiivseire 2014]. Tartu University Marine Institute, Tallinn.

Williams, S. L., and Grosholz, E. D., 2008. The Invasive Species Challenge in Estuarine and Coastal Environments: Marrying Management and Science. Estuaries and Coasts, 31(1):3-20.

WWF, 2011. Baltic Sea Scorecard 2011 Report. World Wide Fund for Nature, WFF Baltic Ecoregion Programme.

Yeo, I. K., and Johnson, R. A., 2000. A new family of power transformations to improve normality or symmetry. Biometrika, 87(4):954-959. 
Table 1. Attribute and attribute levels used in the discrete choice experiment

\begin{tabular}{|c|c|c|c|}
\hline Attribute & Level & Description & $\begin{array}{c}\text { Corresponding } \\
\text { Scenario }\end{array}$ \\
\hline \multirow{4}{*}{$\begin{array}{l}\text { FLS - frequency of } \\
\text { large-scale spills }\end{array}$} & rarely & once in 300 years & GES \\
\hline & sometimes & once in 150 years & \\
\hline & often & once in 10 years & \\
\hline & very often & more than once in 2 years & status quo \\
\hline \multirow{4}{*}{$\begin{array}{l}P R S \text { - probability of } \\
\text { reaching the shore }\end{array}$} & low & $25 \%$ & GES \\
\hline & average & $50 \%$ & \\
\hline & high & $75 \%$ & \\
\hline & very high & $99 \%$ & status quo \\
\hline \multirow{3}{*}{ WQ - water quality } & good & $\begin{array}{c}\text { Water is rarely unclean; Water } \\
\text { transparency (on average) in Pärnu Bay - } \\
\text { less than } 2 \mathrm{~m} \text {, Tallinn Bay }-5 \mathrm{~m} \text {, open parts } \\
\text { of Gulf of Finland }-6 \mathrm{~m} \text {; Algae washes } \\
\text { ashore after large storms }\end{array}$ & GES \\
\hline & moderate & $\begin{array}{c}\text { Water is unclean every } 2-3^{\text {rd }} \text { summer; } \\
\text { Water transparency (on average) in Pärnu } \\
\text { Bay - less than } 1,5 \mathrm{~m} \text {, Tallinn Bay - } 4 \mathrm{~m} \text {, } \\
\text { open parts of Gulf of Finland }-5 \mathrm{~m} \text {; Algae } \\
\text { washes ashore every } 2-3^{\text {rd }} \text { summer in small } \\
\text { amounts. }\end{array}$ & \\
\hline & poor & $\begin{array}{l}\text { Water is unclean every summer; Water } \\
\text { transparency (on average) in Pärnu Bay - } \\
\text { less than } 1 \mathrm{~m} \text {, Tallinn Bay - } 3 \mathrm{~m} \text {, open parts } \\
\text { of Gulf of Finland - } 4 \text { m; Algae washes } \\
\text { ashore every summer in large amounts. }\end{array}$ & status quo \\
\hline \multirow{3}{*}{$\begin{array}{l}\text { NIS - new non- } \\
\text { indigenous species }\end{array}$} & $\begin{array}{c}\text { in } \\
\text { exceptional } \\
\text { cases }\end{array}$ & $\begin{array}{c}\text { not more often than } 1 \text { new species in } 50 \\
\text { years (on average) }\end{array}$ & GES \\
\hline & rarely & 1 new species on average in $15-20$ years & \\
\hline & often & 1 new species on average in 1.5 years & status quo \\
\hline \multirow{2}{*}{$\begin{array}{l}\text { Additional cost to } \\
\text { respondent's } \\
\text { household }\end{array}$} & \multirow{2}{*}{\multicolumn{2}{|c|}{$\begin{array}{c}2,5,10,20 \text { EUR } \\
\text { O EUR }\end{array}$}} & \\
\hline & & & status quo \\
\hline
\end{tabular}


Table 2. The results of the MNL and MXL models of consumers' WTP based on the discrete choice experiment data

$S Q$ - alternative specific constant for the 'No additional actions' alternative FLS - frequency of large-scale spills reduction

$\lambda_{F L S}$ - transformation parameter

PRS - probability of pollution reaching the shore reduction

$\lambda_{P R S}$ - transformation parameter

$W Q$ - water quality

= moderate

$W Q$ - water quality

= good

NIS - new non-indigenous species

= rarely

NIS - new non-indigenous species

= in exceptional cases

$\sigma_{i} a_{i}$ - the scale-cost parameter

\begin{tabular}{|c|c|c|}
\hline $\begin{array}{c}\text { Without } \\
\text { non-linear } \\
\text { transformatio }\end{array}$ & $\begin{array}{c}\text { With } \\
\text { non-linear } \\
\text { transformatio }\end{array}$ & $\begin{array}{c}\text { Without } \\
\text { non-linear } \\
\text { transformation }\end{array}$ \\
\hline
\end{tabular}

MXL

\begin{tabular}{cccccc}
\hline coef. & coef. & mean & s.dev. & mean & s.dev. \\
(s.e.) & $($ s.e. $)$ & $($ s.e. $)$ & $($ s.e. $)$ & $($ s.e. $)$ & $(10)$. \\
\hline $6.6292 * * *$ & $7.8028 * * *$ & $-98.2792^{* * *}$ & $116.9318^{* * *}$ & $-104.5478 * * *$ & $122.2701 * * *$ \\
$(2.4876)$ & $(2.6427)$ & $(7.9324)$ & $(10.1870)$ & $(8.9973)$ & $(10.9591)$ \\
$37.1086 * * *$ & 6.1752 & $35.7191^{* * *}$ & $46.3205^{* * *}$ & $3.2912 * *$ & $4.4793^{* *}$ \\
$(4.3958)$ & $(4.4830)$ & $(3.2746)$ & $(4.1092)$ & $(1.6400)$ & $(2.1152)$
\end{tabular}

(2.4121) (1.5758)

\begin{tabular}{cccccc}
$25.1105 * * *$ & $53.8658 * * *$ & $26.5272 * * *$ & $38.8820 * * *$ & $38.1975 * * *$ & $55.3567 * * *$ \\
$(3.1435)$ & $(15.6452)$ & $(2.5809)$ & $(3.4538)$ & $(6.7167)$ & $(9.1584)$ \\
& -1.6588 & & & -0.1368 & \\
& $(1.1537)$ & & & $(0.5461)$ & \\
$16.9676 * * *$ & $17.0393 * * *$ & $14.2340 * * *$ & $16.6899 * * *$ & $14.7742 * * *$ & $16.2673 * * *$ \\
$(2.1219)$ & $(2.1033)$ & $(1.4736)$ & $(1.7839)$ & $(1.4536)$ & $(1.7566)$ \\
$17.8655 * * *$ & $17.6855 * * *$ & $17.6392 * * *$ & $29.9336 * * *$ & $18.1852 * * *$ & $29.4108 * * *$ \\
$(2.0180)$ & $(1.9863)$ & $(1.8297)$ & $(2.4161)$ & $(1.8189)$ & $(2.3450)$ \\
$9.5320 * * *$ & $9.1505^{* * *}$ & $8.4237 * * *$ & $12.3205 * * *$ & $8.9536 * * *$ & $13.0148 * * *$ \\
$(1.6998)$ & $(1.6719)$ & $(1.3405)$ & $(1.5547)$ & $(1.2618)$ & $(1.5359)$ \\
$10.8070 * * *$ & $10.6060 * * *$ & $10.5740 * * *$ & $14.2640 * * *$ & $11.0195 * * *$ & $14.1086 * * *$ \\
$(1.7231)$ & $(1.7124)$ & $(1.2923)$ & $(1.7252)$ & $(1.2017)$ & $(1.5564)$ \\
$2.5820 * * *$ & $2.6025 * * *$ & $1.7813 * * *$ & $1.5076 * * *$ & $1.7833 * * *$ & $1.5289 * * *$ \\
$(0.2423)$ & $(0.2431)$ & $(0.0808)$ & $(0.1064)$ & $(0.0789)$ & $(0.0941)$ \\
\hline
\end{tabular}

Model diagnostics

Log-likelihood (constants only)

Log-likelihood

McFadden's pseudo- ${ }^{2}$

Ben-Akiva-Lerman's pseudo- $\mathrm{R}^{2}$

$\mathrm{AIC} / n$

$n$ (observations)

k (parameters)

$\begin{array}{cc}-6,984.0775 & -6,984.0775 \\ -6,750.4291 & -6,742.8104 \\ 0.0335 & 0.0345 \\ 0.3724 & 0.3730 \\ 2.0480 & 2.0463 \\ 6,600 & 6,600 \\ 8 & 10\end{array}$

With

non-linear transformation

Notes: $\mathrm{MXL}=$ mixed logit model; $\mathrm{MNL}=$ multinomial logit model; $*, * *$ and $* * *$ represent statistical significance at the $10 \%, 5 \%$ and $1 \%$ level, respectively. Coef. - coefficient, s.e. - standard error, s.dev. - standard deviation. AIC - Akaike Information Criterion. 
Table 3. Respondents' mean willingness to pay (in EUR) for reaching Good Environmental Status in Estonian marine waters, as indicated by the MXL models with and without non-linear transformations

\begin{tabular}{lcc}
\hline & $\begin{array}{c}\text { Welfare measure implied by } \\
\text { the model with } \\
\text { non-linear transformations }\end{array}$ & $\begin{array}{c}\text { Welfare measure implied by } \\
\text { the model without } \\
\text { non-linear transformations }\end{array}$ \\
\cline { 2 - 3 } WTP (s.e.) & $65.73^{* * *}(8.16)$ & $65.52 * * *(5.50)$ \\
$95 \%$ confidence interval & $48.09-77.02$ & $54.70-76.31$ \\
\hline
\end{tabular}




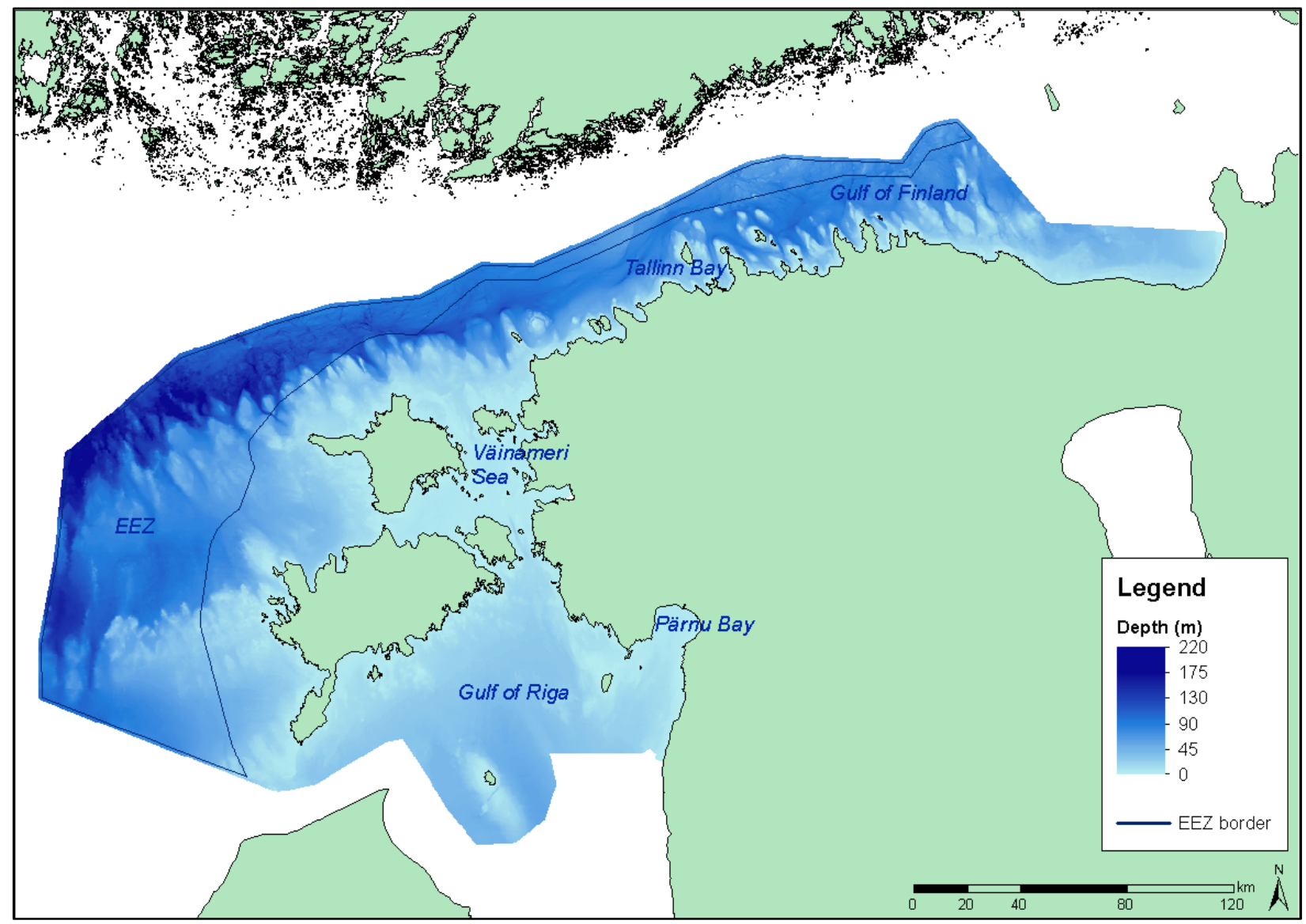

Figure 1. Map of Estonian Marine Waters 


\begin{tabular}{|c|c|c|c|c|}
\hline \multicolumn{2}{|l|}{ Problem } & Alternative $\mathrm{A}$ & Alternative B & $\begin{array}{c}\text { No additional } \\
\text { actions }\end{array}$ \\
\hline \multirow{2}{*}{$\begin{array}{l}\text { Large-scale } \\
\text { pollution with } \\
\text { oil and } \\
\text { chemicals }\end{array}$} & $\begin{array}{l}\text { Cases of Large-scale } \\
\text { pollution of marine } \\
\text { waters }\end{array}$ & rarely & often & very often \\
\hline & $\begin{array}{l}\text { Probability that pollution } \\
\text { reaches the shore }\end{array}$ & low & very high & very high \\
\hline \multicolumn{2}{|c|}{ Water quality for recreation } & poor & moderate & poor \\
\hline \multicolumn{2}{|c|}{$\begin{array}{l}\text { Introduction of new non-indigenous } \\
\text { species }\end{array}$} & often & $\begin{array}{c}\text { in exceptional } \\
\text { cases }\end{array}$ & often \\
\hline \multicolumn{2}{|c|}{ Annual cost to your household (EUR) } & 10 & 20 & 0 \\
\hline \multicolumn{5}{|c|}{ Alternative $\mathrm{A}$} \\
\hline \multicolumn{5}{|c|}{$\bigcirc$ Alternative $\mathrm{B}$} \\
\hline \multicolumn{5}{|c|}{$\bigcirc$ No additional actions } \\
\hline
\end{tabular}

Figure 2. Example choice task used in the questionnaire 
Figure 3. The implied Willingness To Pay for a reduction in the expected frequency of major oil or chemical spills (left) and the probability that pollution will reach the shore (right)
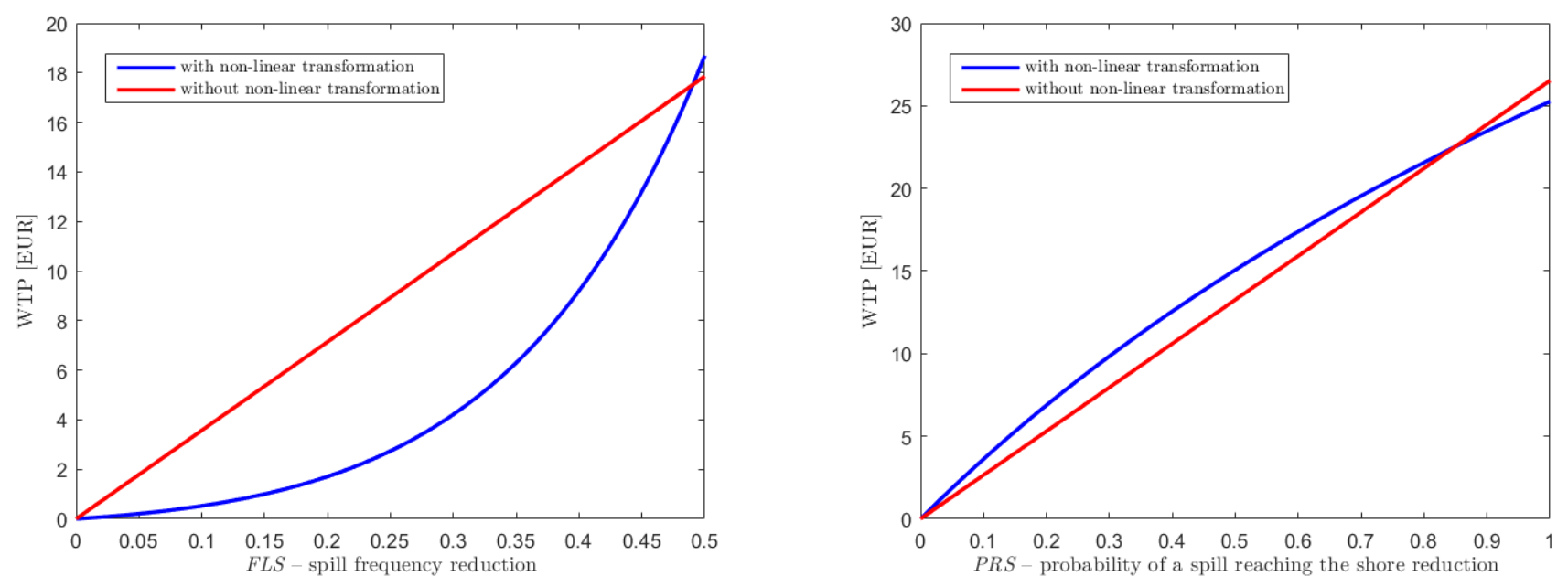